\title{
Health-related quality of life in dialysis patients with constipation: a cross-sectional study
}

This article was published in the following Dove Press journal:

Patient Preference and Adherence

17 June 2013

Number of times this article has been viewed

\author{
JiSheng Zhangl,* \\ CongYang Huangl,* \\ YanLi Li' \\ Jun Chen² \\ FangYuan Shen' \\ Qiang $\mathrm{Yao}^{3}$ \\ JiaQi Qian ${ }^{4}$ \\ BeiYan Bao' \\ XuPing $\mathrm{YaO}^{5}$
}

'Division of Nephrology, School of Medicine, Ningbo Urology and Nephrology Hospital, Ningbo

University, Ningbo, Zhejiang, People's

Republic of China; ${ }^{2}$ Blood Purification

Center, School of Medicine, Ningbo

Urology and Nephrology Hospital,

Ningbo University, Ningbo, Zhejiang,

People's Republic of China; 'Baxter

Healthcare Pty Ltd, Shanghai, People's

Republic of China; ${ }^{4}$ Division of

Nephrology, Renji Hospital, Shanghai

Jiao Tong University School of

Medicine, Shanghai, People's Republic

of China; ${ }^{5}$ Division of Urology,

School of Medicine, Ningbo Urology

and Nephrology Hospital, Ningbo

University, Ningbo, Zhejiang, People's

Republic of China

*These authors contributed equally to this work

Correspondence: BeiYan Bao Division of Nephrology,

School of Medicine, Ningbo Urology

and Nephrology Hospital,

Ningbo University, Ningbo, Zhejiang,

People's Republic of China

Tel +865748303 929l

Fax +86 57483038510

Email beiyan_bao@I63.com
Objectives: To evaluate differences in the health-related quality of life (HRQoL) between patients with constipation receiving hemodialysis (HD) and those receiving peritoneal dialysis (PD).

Methods: In this cross-sectional study, 605 dialysis patients (478 HD cases and 127 PD cases; all patients were older than 18 years) from our hospital were included. A questionnaire was used to evaluate their constipation statuses. The effect of constipation on HRQoL was assessed, using the Chinese version of the 12-item short-form (SF-12) general health survey. Karnofsky score, sociodemographic, and clinical data were also collected. We performed multiple logistic regression analysis to define independent risk factors for constipation and impaired HRQoL.

Results: A total of 605 participants (326 men [53.9\%] and 279 women [46.1\%]) were surveyed. The incidence of constipation was $71.7 \%$ in HD patients and $14.2 \%$ in PD patients. Dialysis patients with constipation had significantly lower mean SF-12 Physical Component Summary scale and Mental Component Summary scale scores than the nonconstipation group $(P<0.05)$, whereas HD patients had better SF-12 Physical Component Summary and Mental Component Summary scores than PD patients $(P<0.05)$. When we performed multivariate logistic regression analysis, dialysis modality, diabetes, and the number of constipation-related medications were three independent risk factors associated with constipation. As for impaired HRQoL in the constipated dialysis population, dialysis modality was found to be another independent risk factor in addition to age and diabetes.

Conclusion: PD patients with constipation had worse HRQoL than HD control participants. We should pay more attention to the patients with constipation receiving $\mathrm{PD}$, as peritonitis caused by constipation was associated with a higher mortality.

Keywords: constipation, health-related quality of life, dialysis, SF-12

\section{Introduction}

Constipation is defined by the new Rome III criteria. ${ }^{1,2}$ It is estimated that $12 \%$ of people worldwide are suffering from self-defined constipation, ${ }^{3}$ and a third of the population in Western industrial countries suffers from constipation at least from time to time. Constipation is a more common problem for patients receiving hemodialysis (HD), although the increased incidence of constipation in long-term dialysis patients is based on self-reported data. ${ }^{4}$ Some studies have shown that patients with end-stage renal disease who are receiving dialysis suffering from constipation account for $53 \%$ ( $8 \%$ to $57 \%){ }^{5,6}$ Constipation tends to be poorly understood and inadequately treated. ${ }^{7}$ Patients with constipation reported significantly lower levels of health-related quality of life (HRQoL) than the general population, but the specific mechanisms through 
which this relationship occurs were unclear. ${ }^{8,9}$ Constipation might generate considerable suffering for patients because of the unpleasant physical symptoms and psychological preoccupations, ${ }^{10-13}$ and it could be caused by technique failure and poor dialysis efficiency in patients receiving peritoneal dialysis (PD). ${ }^{14}$ However, very few studies have evaluated the effect of constipation on HRQoL in the population receiving dialysis. Regarding patients receiving either treatment modality, the HRQoL differences reported in the relevant literature were inconclusive. However, little was known about the HRQoL differences between HD and PD groups with constipation.

The intention of the present study was to evaluate the prevalence of constipation according to Rome III criteria in patients receiving dialysis, to determine whether HRQoL is impaired in patients receiving dialysis who have constipation, and to compare HRQoL between the two dialysis groups with constipation.

\section{Study design, materials, and methods}

In this cross-sectional study, we included a total of 605 patients receiving dialysis (478 HD cases and 127 PD cases) from our unit in Ningbo, in southeast China. All patients aged 18 years or older who had received HD or PD for more than 3 months were screened for participation. Signed informed consent was required for enrollment, after which patients received oral and written information about the study. To ensure standardized conditions, selfadministered questionnaires were completed during the regular sessions for patients receiving HD or during the scheduled visit at the outpatient clinic for patients receiving PD. Ethical permission for the study was obtained from the scientific committee of the hospital.

\section{Study inclusion and exclusion criteria}

The participants (both HD and PD) were selected according to the following criteria: diagnosis of end-stage renal disease, receiving current conventional HD (three times per week) or maintenance PD treatment, older than 18 years, voluntary participation, and signed consent form. Exclusion criteria were cognitive deficits such as considerable memory loss, confusion/dementia, and intellectual disability; being illiterate and/or being incapable of answering the questionnaire (difficulty in understanding the questions, visual or hearing impairment); having a serious illness in an acute treatment phase or receiving palliative care; and having a history of major abdominal surgery.

\section{Demographic and clinical data at baseline}

Demographic data including employment status, education, and the number of constipation-related medications were collected by questioning the patients. Age, sex, primary kidney disease for renal failure, dialysis modality, comorbidities, and laboratory data including hemoglobin, serum albumin, serum potassium, and serum calcium levels were gathered from medical records.

\section{Definition}

The Rome III criteria in 2006 for constipation include having at least two of the following: straining during defecation $25 \%$ of the time, lumpy or hard stools in $25 \%$ of defecation, sensation of incomplete evacuation in $25 \%$ of defecation, sensation of anorectal obstruction/blockage in $25 \%$ of defecation, need for manual maneuvers to facilitate defecation $25 \%$ of the time, and fewer than three defecations per week. In addition, patients should rarely have loose stools without laxatives and should not have irritable bowel syndrome.

\section{Functional status, depression, and HRQoL assessment}

Functional status was evaluated using the Karnofsky score. ${ }^{15}$ The Chinese version of Beck's Depression Inventory was also used to evaluate depression in our patients receiving dialysis. ${ }^{16}$ Comorbidity was scored on the number of comorbid conditions using the comorbidity index, according to a previous study. ${ }^{17}$

HRQoL was assessed using the Physical Component Summary scale (PCS) and the Mental Component Summary scale (MCS) scores from the 12-item short-form (SF-12; version 2), which is a self- assessment of physical and mental health. SF-12 provides similar predictions of quality of life to those of SF-36 and may serve as an applicable clinical tool because it requires less time to complete. ${ }^{18}$ The version used in this study reflects HRQoL over the previous 4 weeks. SF-12 was scored from 0 to 100 , with higher scores indicating better HRQoL.

\section{Statistics}

All values were expressed as the mean \pm standard deviation, median 25 th or 75 th percentile, or percentage, as appropriate, and $P<0.05$ was considered statistically significant. Comparisons among quartiles were assessed with oneway analysis of variance, Kruskal-Wallis, or $\chi^{2}$ test, as appropriate.

Because age, sex, and primary kidney disease were considered possible confounders, all analyses were also adjusted 
for those variables. Marital stage, employment status, health insurance, living alone, education, Karnofsky score, Beck Depression Inventory, and the comorbidity index could have influenced the HRQoL. Therefore, all analyses were adjusted for those variables in addition to the previously mentioned possible confounders.

Odds ratios and $95 \%$ confidence intervals (95\% CIs) were calculated by means of logistic regression models for the prevalence of constipation, with adjustment for age, sex, and primary disease. We performed multiple logistic regression analysis to define independent risks for constipation. Multiple linear regression analysis was used to define independent risk factors associated with impaired HRQoL in dialysis patients with constipation. All statistical analyses were evaluated using SPSS 17.00 (IBM Corporation, Armonk, NY, USA).

\section{Results}

\section{Patient characteristics}

The 605 respondents had a mean age of $50.0 \pm 3.2$ years. Their demographic and socioeconomic features are shown in Tables 1 and 2. The two groups were slightly different in age, employment status, and number of constipation-related medications.

\section{Incidence of constipation in each group}

The incidences of constipation are summarized in Table 3 . The relative risk for constipation was 4.17 times higher in the group receiving HD compared with the PD group, adjusting for age, sex, and primary disease (95\% CI, 2.98-6.96; $P<0.05)$.

\section{Risk factors for constipation in the dialysis population}

In multiple logistic regression analysis, dialysis modality was the independent risk factor associated with constipation (odds ratio [OR], 2.72; 95\% CI, 2.41-5.95; $P<0.01)$. Age and the number of constipation-related medications were two other independent risk factors for HRQoL.

\section{Risk factors for impaired HRQoL in the constipated dialysis population}

When we performed multiple linear regression analysis, dialysis modality was one of several independent risk factors for impaired HRQoL in the constipated dialysis population (OR, $1.63 ; 95 \% \mathrm{CI}, 1.23-3.47 ; P<0.05)$. In addition to dialysis modality, age and diabetes were additional risk factors.
Table I Sociodemographic and clinical data of the HD and PD participants

\begin{tabular}{|c|c|c|c|}
\hline Characteristics & $\begin{array}{l}\text { HD } \\
(n=478)\end{array}$ & $\begin{array}{l}P D \\
(n=127)\end{array}$ & $P$-value ${ }^{a}$ \\
\hline Age in years (mean $\pm S D)$ & $53.0 \pm 14.2$ & $45.2 \pm 13.1$ & $<0.05$ \\
\hline Female sex, n (\%) & $221(46.2)$ & $58(45.7)$ & 0.91 \\
\hline $\begin{array}{l}\text { Marital status (married), } \\
\text { n (married, \%) }\end{array}$ & $353(73.8)$ & $93(73.2)$ & 0.89 \\
\hline $\begin{array}{l}\text { Employment status (employed), } \\
\text { n (employed \%) }\end{array}$ & $231(48.3)$ & $100(82.7)$ & $<0.01$ \\
\hline Primary kidney disease, n (\%) & & & 0.92 \\
\hline Nephritis & $278(58.1)$ & $70(55.1)$ & \\
\hline Hypertensive nephrosclerosis & $24(5.0)$ & $6(4.7)$ & \\
\hline Diabetic nephropathy & $60(12.6)$ & $20(15.7)$ & \\
\hline Polycystic kidney disease & $31(6.5)$ & $8(6.3)$ & \\
\hline Other & $85(17.8)$ & $23(18.2)$ & \\
\hline Health insurance, $n$ & 478 & 127 & 1.00 \\
\hline Education, $\mathrm{n}$ & & & 0.62 \\
\hline Up to high school & 351 & 96 & \\
\hline Beyond high school & 127 & 31 & \\
\hline Living alone, $\mathrm{n}$ & 36 & 6 & 0.27 \\
\hline $\begin{array}{l}\text { Number of constipation-related } \\
\text { medications }{ }^{\mathrm{b}}, \mathrm{n}\end{array}$ & & & $<0.01$ \\
\hline$<4$ & 53 & 51 & \\
\hline$\geq 4$ & 425 & 76 & \\
\hline $\begin{array}{l}\text { Mean hemoglobin }(g / L) \\
(\text { mean } \pm \text { SD) }\end{array}$ & $11.3 \pm 3.8$ & $11.5 \pm 4.7$ & 0.39 \\
\hline $\begin{array}{l}\text { Mean serum potassium }(\mathrm{mmol} / \mathrm{L}) \\
(\text { mean } \pm \mathrm{SD})\end{array}$ & $3.9 \pm 1.5$ & $3.8 \pm 0.9$ & 0.48 \\
\hline $\begin{array}{l}\text { Mean serum calcium }(\mathrm{mmol} / \mathrm{L}) \\
(\text { mean } \pm \mathrm{SD})\end{array}$ & $2.1 \pm 0.8$ & $2.1 \pm 0.4$ & 0.76 \\
\hline $\begin{array}{l}\text { Mean serum albumin }(g / L) \\
(\text { mean } \pm S D)\end{array}$ & $35.3 \pm 4.1$ & $34.8 \pm 8.7$ & 0.56 \\
\hline $\begin{array}{l}\text { Mean time receiving dialysis } \\
\text { in months (mean } \pm S D \text { ) }\end{array}$ & $53.4 \pm 14.9$ & $49.6 \pm 10.4$ & 0.09 \\
\hline Comorbidity index $($ mean $\pm S D)$ & $6.3 \pm 2.7$ & $5.9 \pm 3.2$ & 0.45 \\
\hline $\begin{array}{l}\text { Karnofsky score median } \\
(\text { mean } \pm S D)\end{array}$ & $78.6 \pm 8.8$ & $80.2 \pm 10.3$ & 0.37 \\
\hline $\begin{array}{l}\text { Beck depression inventory } \\
\text { score (mean } \pm S D \text { ) }\end{array}$ & $12.8 \pm 8.0$ & $13.7 \pm 8.6$ & 0.81 \\
\hline
\end{tabular}

Notes: aDifferences in proportions were tested using the Pearson Chi-square test; differences in means were tested using an independent $t$-test or the Mann-Whitney test; ${ }^{b}$ medications associated with constipation include calcium channel blockers, charcoal, ${ }^{19}$ iron supplements, ${ }^{20}$ phosphate binder, ${ }^{21}$ and antidepressants. ${ }^{22-25}$

Abbreviations: HD, hemodialysis; PD, peritoneal dialysis; $n$, number; $S D$, standard deviation.

\section{Impaired HRQoL in constipated dialysis patients}

Table 4 presents the HRQoL outcomes for PD and HD patients with constipation. Dialysis patients with constipation had significantly lower mean SF-12 PCS and MCS scores than the nonconstipation control group $(P<0.05$; Table 5), and constipated HD patients had better SF-12 PCS and MCS scores than constipated PD patients. 
Table 2 Sociodemographic and clinical data between constipation and nonconstipation groups

\begin{tabular}{|c|c|c|c|}
\hline Characteristics & $\begin{array}{l}\text { Constipated patients } \\
(n=361)\end{array}$ & $\begin{array}{l}\text { Nonconstipated patients } \\
(n=244)\end{array}$ & $P$-value \\
\hline Age in years (mean $\pm S D)$ & $51.8 \pm 15.4$ & $46.5 \pm 12.0$ & $<0.05$ \\
\hline Female sex, $\mathrm{n}(\%)$ & $170(47.1)$ & $109(44.7)$ & 0.56 \\
\hline Marital status, $\mathrm{n}$ (married, \%) & $235(65.1)$ & $161(66.0)$ & 0.82 \\
\hline Employment status, n (employed, \%) & $121(33.3)$ & $215(88.1)$ & $<0.05$ \\
\hline Primary kidney disease, n (\%) & & & $<0.05$ \\
\hline Nephritis & $168(46.5)$ & $180(73.8)$ & \\
\hline Hypertensive nephrosclerosis & $20(5.5)$ & $10(4.1)$ & \\
\hline Diabetic nephropathy & $57(15.8)$ & $23(9.4)$ & \\
\hline Polycystic kidney disease & $22(6.1)$ & $17(7.0)$ & \\
\hline Other & $94(26.1)$ & $14(5.7)$ & \\
\hline Health insurance, $n$ & 361 & 244 & 1.00 \\
\hline Education, $\mathrm{n}$ & & & $<0.05$ \\
\hline Up to high school & 265 & 198 & \\
\hline Beyond high school & 96 & 46 & \\
\hline Living alone, $\mathrm{n}$ & 29 & 13 & 0.2 \\
\hline Number of constipation-related medications, $\mathrm{n}$ & & & $<0.05$ \\
\hline$<4$ & 34 & 70 & \\
\hline$\geq 4$ & 327 & 174 & \\
\hline Mean hemoglobin $(g / L)($ mean $\pm S D)$ & $1 \mathrm{I} .4 \pm 5.5$ & $11.2 \pm 1.7$ & $>0.05$ \\
\hline Mean serum potassium $(g / L)($ mean $\pm S D)$ & $3.5 \pm 1.4$ & $4.4 \pm 1.3$ & $<0.05$ \\
\hline Mean serum calcium $(g / L)($ mean $\pm S D)$ & $2.4 \pm 0.6$ & $2.0 \pm 0.9$ & $<0.05$ \\
\hline Mean serum albumin $(g / L)($ mean $\pm S D)$ & $35.3 \pm 6.8$ & $35.0 \pm 2.5$ & 0.63 \\
\hline Mean time receiving dialysis in months (mean $\pm S D$ ) & $52.6 \pm 12.4$ & $52.6 \pm 16.2$ & 0.42 \\
\hline Comorbidity index (mean $\pm S D)$ & $6.1 \pm 1.5$ & $6.4 \pm 4.7$ & 0.33 \\
\hline Karnofsky score median (mean \pm SD) & $77.6 \pm 9.7$ & $80.9 \pm 8.2$ & 0.14 \\
\hline Beck Depression Inventory score (mean \pm SD) & $14.8 \pm 7.7$ & $10.3 \pm 8.8$ & $<0.05$ \\
\hline
\end{tabular}

Abbreviations: $n$, number; SD, standard deviation.

\section{Discussion}

This study provided a comprehensive and detailed description of the incidence of constipation and its effect on HRQoL in the dialysis population. The incidence of constipation based on Rome III criteria was $71.7 \%$ in HD patients and $14.2 \%$ in PD patients. According to early reports, $40 \%$ to $70 \%$ of HD patients and $16.0 \%$ to $28.9 \%$ of PD patients had constipation. ${ }^{26,27}$ Previous studies showed that the lower prevalence of constipation in PD patients might be caused by the low rate of constipating drug administration, dialysis modality-based lifestyle, nutrition, higher total dietary fiber intake, the warm dialysate in the peritoneum, and little chance to defecate, or failure to respond to the desire to defecate, during HD therapy. ${ }^{28}$ Apart from these causes, employment status, diabetes, and mean time receiving dialysis (in months) could all affect the incidence of constipation. As for employment status, patients receiving PD had more time and a higher number of chances to work and exercise with employment. In addition, employment could improve patients' psychological health, lowering the incidence of constipation. Several studies also found that constipation was among the most frequent of gastrointestinal symptoms in patients with diabetes mellitus, which contributed to the higher incidence of constipation in patients receiving HD. ${ }^{29-31}$

We also examined the effect of constipation on HRQoL and compared HRQoL between the two modalities with constipation. The relative differences in HRQoL between the two modalities were not clearly known before. Harris et $\mathrm{al}^{32}$ thought there were no significant HRQoL differences between HD and PD patients, but others thought some treat-

Table 3 Incidence of constipation in each patient group

\begin{tabular}{llllll}
\hline Patient group & Total & $\begin{array}{l}\text { Constipated } \\
(\mathbf{n})\end{array}$ & $\begin{array}{l}\text { Nonconstipated } \\
(\mathbf{n})\end{array}$ & $\begin{array}{l}\text { Odds ratio } \\
\text { (95\% confidence interval)* }\end{array}$ \\
\hline Hemodialysis & 478 & $343(71.7 \%)$ & $135(28.3 \%)$ & $4.17(2.98-6.96)$ & $<0.001$ \\
Peritoneal dialysis & 127 & $18(14.2 \%)$ & $109(85.8 \%)$ & Reference & $<0.001$ \\
\hline
\end{tabular}

Note: *Adjusted for age, sex, and primary disease.

Abbreviation: $\mathrm{n}$, number. 
Table 4 Health-related quality of life in constipated hemodialysis and peritoneal dialysis patients

\begin{tabular}{llll}
\hline $\begin{array}{l}\text { Health-related } \\
\text { quality of life }\end{array}$ & $\begin{array}{l}\text { Hemodialysis } \\
(\mathbf{n}=\mathbf{3 4 3})\end{array}$ & $\begin{array}{l}\text { Peritoneal } \\
\text { dialysis } \\
\mathbf{( n = 1 8 )}\end{array}$ & $\begin{array}{l}\text { P-value for } \\
\text { difference } \\
\text { in pattern* }\end{array}$ \\
\hline $\begin{array}{l}\text { SF-I2 PCS } \\
\text { mean (SD) }\end{array}$ & $35.4(5.8)$ & $31.6(6.7)$ & $<0.05$ \\
$\begin{array}{l}\text { SF-I2 MCS } \\
\text { mean (SD) }\end{array}$ & $38.9(10.2)$ & $35.3(7.3)$ & $<0.05$ \\
\hline
\end{tabular}

Notes: a ${ }^{A}$ higher score indicates better quality of life. *Adjusted for age, sex, primary disease, marital stage, employment status, health insurance, living alone, education, Karnofsky score, Beck Depression Inventory, and comorbidity index.

Abbreviations: $n$, number; SD, standard deviation; SF-12, 12-item short form general health survey; PCS, physical health component summary; MCS, mental health component summary.

ments were better for HD patients but others were better for PD patients. ${ }^{33}$ The results of our study demonstrate an effect of constipation on both the mental and physical components of HRQoL in the dialysis population.

Patients with constipation often had impaired HRQoL. Dialysis patients with constipation had significantly lower mean SF-12 PCS and MCS scores than those patients in the matched control group. In addition, we also observed better SF-12 PCS and MCS scores in HD patients than in PD patients with constipation, although the prevalence of constipation in HD patients was higher. The reason might be that the severity of constipation was mild and could be controlled easily.

It is well known that psychological indicators tend to favor PD patients. This is probably because PD treatment offers increased autonomy and control, flexibility in daily life, and reduction of dietary and social restrictions. As for PD patients with constipation, peritonitis resulting from colonic perforation was associated with a higher mortality. ${ }^{34}$ In several studies, HD was reported to have better scores than PD with regard to physical well-being; ${ }^{35}$ this was also found to be the case in our study. These findings might have a relevance to the previously mentioned higher level of anxiety in early

Table 5 Health-related quality of life between patients with constipation and those without constipation

\begin{tabular}{llll}
\hline $\begin{array}{l}\text { Health-related } \\
\text { quality of life }\end{array}$ & $\begin{array}{l}\text { Constipated } \\
(\mathbf{n}=\mathbf{3 6} \text { I) }\end{array}$ & $\begin{array}{l}\text { Nonconstipated } \\
(\mathbf{n}=\mathbf{2 4 4})\end{array}$ & $\begin{array}{l}\text { P-value* } \\
\text { SF-I2 PCS }\end{array}$ \\
$\begin{array}{l}\text { mean (SD) } \\
\text { SF-I2 MCS }\end{array}$ & $35.2(5.8)$ & $43.7(8.9)$ & $<0.05$ \\
mean (SD) & $38.7(10.1)$ & $45.2(13.1)$ & $<0.05$ \\
\hline
\end{tabular}

Notes: a $\mathrm{A}$ higher score indicates better quality of life; $*$ Adjusted for age, sex, primary disease, marital stage, employment status, health insurance, living alone, education, Karnofsky score, Beck Depression Inventory, and comorbidity index.

Abbreviations: n, number; SF-12, I2-item short form general health survey; PCS, physical health component summary; MCS, mental health component summary. starters of PD treatment, as the median duration of PD was shorter than that of HD. ${ }^{36}$ All these factors could contribute to the lower SF-12 PCS and MCS scores in PD patients in our study. The reason for impaired HRQoL in dialysis was painful defecation and abdominal pain. ${ }^{37,38}$ Indeed, in Table 2, we show that patients with constipation had higher depression scores $(P<0.05)$.

Because of its significant effect on HRQoL, ${ }^{39}$ we should pay more attention to constipation. Medical therapy with polyethylene glycol or lactulose should be favored in longterm treatment, and psychodiagnostic queries concerning fear should be included in the diagnostic procedures. Biofeedback was an effective therapy in these cases, especially with pelvic floor dyssynergia. Surgical interventions were rarely indicated or successful, with the exception of chronic outlet obstruction with severe anatomic changes. ${ }^{40}$

\section{Conclusion}

We evaluated the prevalence of constipation in the dialysis population and found differences between the two treatment modalities. We also demonstrated the significant effect of constipation on HRQoL. Constipation had a negative effect on HRQoL, and more obvious effects on HRQoL in PD patients than in HD patients. We should pay more attention to the PD patients with constipation, as peritonitis caused by constipation was associated with a higher mortality.

Further, because of missing information in the patients' records, there were some missing values for the latter variable. The data of this study were cross-sectional, and thus did not provide insight into the longitudinal effects of constipation on HRQoL in the dialysis population. Finally, evidence provided by this study could be extended by the control of the above issues and the use of even larger samples. Thus, more clinical multicenter studies are needed to clarify the real incidence of constipation and its longitudinal effects on HRQoL in the dialysis population.

\section{Disclosure}

The authors report no conflicts of interest in this work.

\section{References}

1. Lindberg G, Hamid SS, Malfertheiner P, et al; for World Gastroenterology Organisation. World Gastroenterology Organisation global guideline: Constipation - a global perspective. J Clin Gastroenterol. 2011;45(6):483-487.

2. Bove A, Pucciani F, Bellini M, et al Consensus statement AIGO/SICCR: diagnosis and treatment of chronic constipation and obstructed defecation (part I: diagnosis). World J Gastroenterol. 2012;18(14): 1555-1564.

3. Lee EJ, Warden S. A qualitative study of quality of life and the experience of complementary and alternative medicine in Korean women with constipation. Gastroenterol Nurs. 2011;34(2):118-127. 
4. Wu MJ, Chang CS, Cheng $\mathrm{CH}$, et al. Colonic transit time in long-term dialysis patients. Am J Kidney Dis. 2004;44(2):322-327.

5. Murtagh FE, Addington-Hall J, Higginson IJ. The prevalence of symptoms in end-stage renal disease: a systematic review. Adv Chronic Kidney Dis. 2007;14(1):82-99.

6. Hammer J, Oesterreicher C, Hammer K, Koch U, Traindl O, Kovarik J. Chronic gastrointestinal symptoms in hemodialysis patients. Wien Klin Wochenschr. 1998;110(8):287-291.

7. Wainwright M, Russell AJ, Yiannakou Y. Challenging the biopsychosocial model in a chronic constipation clinic. Qual Health Res. 2011;21(12):1643-1657.

8. Sun SX, Dibonaventura M, Purayidathil FW, Wagner JS, Dabbous O, Mody R. Impact of chronic constipation on health-related quality of life, work productivity, and healthcare resource use: an analysis of the National Health and Wellness Survey. Dig Dis Sci. 2011;56(9):2688-2695.

9. Albiani JJ, Hart SL, Katz L, et al. Impact of depression and anxiety on the quality of life of constipated patients. J Clin Psychol Med Settings. 2013;20(1):123-132.

10. [No authors listed] Lactitol or lactulose in the treatment of chronic constipation: result of a systematic. J Indian Med Assoc. 2010;108(11):789-792.

11. Wang HF, Lim PS, Kao MD, Chan EC, Lin LC, Wang NP. Use of isomalto-oligosaccharide in the treatment of lipid profiles and constipation in hemodialysis patients. J Ren Nutr. 2001;11(2):73-79.

12. St Peter WL, Clark JL, Levos OM. Drug therapy in haemodialysis patients. Special considerations in the elderly. Drugs Aging. 1998;12(6):441-459.

13. Adams PL, Rutsky EA, Rostand SG, Han SY. Lower gastrointestinal tract dysfunction in patients receiving long-term hemodialysis. Arch Intern Med. 1982;142(2):303-306.

14. Sutton D, Dumbleton S, Allaway C. Can increased dietary fibre reduce laxative requirement in peritoneal dialysis patients? J Ren Care. 2007; 33(4):174-178.

15. Rebollo P, Ortega F, Baltar JM, Alvarez-Ude F, Alvarez Navascués R, Alvarez-Grande J. Is the loss of health-related quality of life during renal replacement therapy lower in elderly patients than in younger patients? Nephrol Dial Transplant. 2001;16(8):1675-1680.

16. Beck AT, Ward CH, Mendelson M, Mock J, Erbaugh J. An inventory for measuring depression. Arch Gen Psychiatry. 1961;4:561-571.

17. Rebollo P, Ortega F, Baltar JM, et al. Health related quality of life (HRQOL) of kidney transplanted patients: variables that influence it. Clin Transplant. 2000;14(3):199-207.

18. Brown EA, Johansson L, Farrington K, et al. Broadening Options for Long-term Dialysis in the Elderly (BOLDE): differences in quality of life on peritoneal dialysis compared to haemodialysis for older patients. Nephrol Dial Transplant. 2010;25(11):3755-3763.

19. Osterhoudt KC, Alpern ER, Durbin D, Nadel F, Henretig FM. Activated charcoal administration in a pediatric emergency department. Pediatr Emerg Care. 2004;20(8):493-498.

20. Agarwal R, Rizkala AR, Bastani B, Kaskas MO, Leehey DJ, Besarab A. A randomized controlled trial of oral versus intravenous iron in chronic kidney disease. Am J Nephrol. 2006;(5):445-454.

21. Segawa H, Furutani J, Miyamoto K. [Pharmacologic intervention for vascular calcification.] Clin Calcium. 2005;15(7):149-154. Japanese [with English abstract].

22. Bouras EP, Tangalos EG. Chronic constipation in the elderly. Gastroenterol Clin North Am. 2009;38(3):463-480.
23. Nehra V, Bruce BK, Rath-Harvey DM, Pemberton JH, Camilleri M. Psychological disorders in patients with evacuation disorders and constipation in a tertiary practice. Am J Gastroenterol. 2000;95(7): $1755-1758$.

24. Chang JY, Locke GR, Schleck CD, Zinsmeister AR, Talley NJ. Risk factors for chronic constipation and a possible role of analgesics. Neurogastroenterol Motil. 2007;19(11):905-911.

25. Talley NJ, Jones M, Nuyts G, Dubois D. Risk factors for chronic constipation based on a general practice sample. Am J Gastroenterol. 2003;98(5):1107-1111.

26. McCrea GL, Miaskowski C, Stotts NA, Macera L, Varma MG. A review of the literature on gender and age differences in the prevalence and characteristics of constipation in North America. J Pain Symptom Manage. 2009;37(4):737-745.

27. Higgins PD, Johanson JF. Epidemiology of constipation in North America: a systematic review. Am J Gastroenterol. 2004;99(4):750-759.

28. Yasuda G, Shibata K, Takizawa T, et al. Prevalence of constipation in continuous ambulatory peritoneal dialysis patients and comparison with hemodialysis patients. Am J Kidney Dis. 2002;39(6):1292-1299.

29. Rodrigues ML, Motta ME. Mechanisms and factors associated with gastrointestinal symptoms in patients with diabetes mellitus. J Pediatr (Rio J). 2012;88(1):17-24.

30. Oh JH, Choi MG, Kang MI, et al. The prevalence of gastrointestinal symptoms in patients with non-insulin dependent diabetes mellitus. Korean J Intern Med. 2009;24(4):309-317.

31. Shakil A, Church RJ, Rao SS. Gastrointestinal complications of diabetes. Am Fam Physician. 2008;77(12):1697-1702.

32. Harris SA, Lamping DL, Brown EA, Constantinovici N; for North Thames Dialysis Study (NTDS) Group. Clinical outcomes and quality of life in elderly patients on peritoneal dialysis versus hemodialysis. Perit Dial Int. 2002;22(4):463-470.

33. de Wit GA, Merkus MP, Krediet RT, de Charro FT. Health profiles and health preferences of dialysis patients. Nephrol Dial Transplant. 2002;17(1):86-92.

34. Yasuda G, Takeshita Y, Kimura T, et al. Constipation occurs less frequently in CAPD patients than in HD patients. Perit Dial Int. $1995 ; 15(6): 283$

35. Klaschik E, Nauck F, Ostgathe C. Constipation - modern laxative therapy. Support Care Cancer. 2003;11(11):679-685.

36. Theofilou P. Quality of life in patients undergoing hemodialysis or peritoneal dialysis treatment. $J$ Clin Med Res. 2011;3(3):132-138.

37. Cain KC, Headstrom P, Jarrett ME, et al. Abdominal pain impacts quality of life in women with irritable bowel syndrome. Am J Gastroenterol. 2006;101(1):124-132.

38. Bharucha AE, Locke GR, Zinsmeister AR, et al. Differences between painless and painful constipation among community women. Am J Gastroenterol. 2006;101(3):604-612.

39. Belsey J, Greenfield S, Candy D, Geraint M. Systematic review: impact of constipation on quality of life in adults and children. Aliment Pharmacol Ther. 2010;31(9):938-949.

40. Vogelsang H, Pfeiffer J, Moser G. [Recommendations on therapy for chronic constipation - working group for functional diagnosis and psychosomatics of the Austrian Society of Gastroenterology and Hepatology.] Z Gastroenterol. 2011;49(2):294-303. German [with English abstract].
Patient Preference and Adherence

\section{Publish your work in this journal}

Patient Preference and Adherence is an international, peer-reviewed, open access journal focusing on the growing importance of patient preference and adherence throughout the therapeutic continuum. Patient satisfaction, acceptability, quality of life, compliance, persistence and their role in developing new therapeutic modalities and compounds to

\section{Dovepress}

optimize clinical outcomes for existing disease states are major areas of interest. This journal has been accepted for indexing on PubMed Central. The manuscript management system is completely online and includes a very quick and fair peer-review system. Visit http://www.dovepress.com/ testimonials.php to read real quotes from published authors. 